\title{
RELIGIÃO COMO CULTURA? AS FESTAS DO DIVINO, O TAMBOR DE MINA E O REGIME PATRIMONIAL
}

\section{RELIGION AS CULTURE? HOLY GHOST FEASTS, TAMBOR DE MINA AND THE HERITAGE REGIME}

\author{
João Leal*
}

\section{Introdução}

Vários autores têm destacado a abertura ao catolicismo que caracteriza o tambor de mina (EDUARDO, 1948; FERRETTI, 1995; LEAL 2017). Uma das expressões dessa abertura prende-se com a cooptação das festas do Divino Espírito Santo (ou festas do Divino) pelos terreiros de tambor de mina ${ }^{1}$. Esta cooptação tem sido trabalhada a partir de vários pontos de vista, que vão desde a exploração dos modos de articulação entre as festas e o culto dos encantados (FERRETTI, 1995; LEAL, 2017) até à sua análise como "festas maiores" dos terreiros de tambor de mina (LEAL, 2014). 0 objetivo deste artigo é examinar uma outra dimen- são das festas: a sua gradual inscrição no "regime patrimonial" (HAFSTEIN, 2004).

De facto, particularmente desde os anos 1990, as festas do Divino têm sido incorporadas nas políticas e práticas de objetificação (HANDLER, 1988) da cultura popular no estado do Maranhão, conduzidas por organismos e por ativistas culturais. Esses processos de objetificação impactaram no modo como as festas são tematizadas a partir das casas de tambor de mina.

Este artigo visa proceder ao exame dessas políticas e práticas e dos seus efeitos nos terreiros. Um deles foi a culturalização das festas, isto é, a sua tematização em torno de ideias sobre cultura, raízes e tradição. Examinarei também os termos dessa culturaliza-

\footnotetext{
* Professor da Faculdade de Ciências Sociais e Humanas da Universidade Nova de Lisboa - NOVA (Lisboa/ PT). E-mail: joao.leal@fcsh.unl.pt

1. Essa abertura ao catolicismo tem sido tematizada sobretudo a partir do conceito de sincretismo (FERRETTI, 1995). Tive ocasião de exprimir as minhas reservas em relação a esse conceito no respeitante à cooptação das festas do Divino pelos terreiros de tambor de mina. Em alternativa propus a expressão "modos de articulação" (LEAL, 2017).
} 
ção. Esta deve ser vista não tanto como um processo de ressignificação radical das festas - como acontece com muitas expressões culturais objetificadas -, mas como um processo de adição de um novo significado "cultural" aos significados religiosos e sociais que continuam a caracterizá-las. Argumentarei também que a objetificação das festas pode ser vista em termos equivalentes aos processos de patrimonialização das religiões afro-brasileiras que, noutros contextos - como na Bahia -, surgem associados à sua reafricanização (SANTOS, J., 2005; SANSI, 2007). Não só o seu efeito é similar - contribuir para inscrever o tambor de mina no regime patrimonial -, como faz sentido que, nas condições de uma religião que tem na abertura ao catolicismo uma das suas características importantes, esse efeito possa ser conseguido por intermédio de uma festa de matriz católica ${ }^{2}$.

\section{As festas do Divino em São Luís}

A importância das festas do Divino no Maranhão, onde terão sido introduzidas por colonos açorianos na primeira metade do século XVII, tem sido sublinhada por diversos autores (EDUARD0, 1948; FERRETTI, 1995; LEAL, 2017). No estado, existem mais de 200 festas recenseadas (GONÇALVES; LEAL, 2016), cerca de 80 das quais se realizam na cidade de São Luís. Embora algumas delas tenham lugar no domingo de
Pentecostes, a maioria realiza-se ao longo do ano e homenageia simultaneamente o Espírito Santo e um santo (ou santa, ou invocação de Nossa Senhora) ${ }^{3}$.

No quadro das festas, o Espírito Santo é usualmente representado - em conjunto com um pombo de madeira e com a bandeira do Espírito Santo -, por intermédio de uma coroa em latão (ou mais raramente em prata), encimada por uma pomba e acompanhada de um cetro. Estes símbolos são instalados na tribuna, um altar ricamente decorado, onde se centra parte importante dos festejos. Como em muitas outras festas populares brasileiras, a festa do Divino surge associada a um mastro, que, para além de assinalar o lugar e o tempo da festa, simboliza também o Espírito Santo.

Nas festas têm um papel de grande importância os impérios: crianças e pré-adolescentes de ambos os sexos, que envergam trajes de gala inspirados em trajes de corte e desempenham os cargos de imperador e imperatriz, mordomo e mordoma régio(a) e mordomo e mordoma mor. Estes cargos são bancados - isto é, patrocinados e pagos - por adultos, geralmente pais ou outros parentes próximos dos meninos e meninas.

A par dos impérios, o outro grupo de protagonistas mais importante das festas é constituído pelas caixeiras: agrupamentos de oito ou mais mulheres - dirigidas por uma caixeira régia -, que, por intermédio de cânti-

2. 0 trabalho de campo que se encontra na base do presente artigo foi realizado no âmbito de uma pesquisa mais vasta - sobre as festas do Divino em terreiros de tambor de mina -, realizada entre 2011 e 2104 , num total de nove meses (LEAL, 2017). Para a realização desse trabalho de campo beneficiei do apoio f1nanceiro da Fundação para a Ciência e Tecnologia de Portugal (através do projecto PTDC/CS -ANT/100037/2008) e da FAPEMA (através de uma bolsa de professor/ pesquisador convidado). Agradeço aos dois pareceristas anônimos deste artigo os seus comentários e sugestões.

3. Uma apresentação mais detalhada das festas do Divino em São Luís, pode ser encontrada em Ferretti (1995; 1999) e em Leal (2017). A descrição mais sintetizada que apresento neste artigo resulta de observações realizadas em vários terreiros, onde, apesar de algumas variações, as festas apresentam um script ritual dotado de alguma constância. 
cos acompanhados pelas caixas, asseguram a direção musical dos festejos e se encarregam de louvar o Espírito Santo e a santa (ou santo ou invocação de Nossa Senhora) celebrada em conjunto com o Divino (GOUVEIA, 2001; PACHECO; GOUVEIA; ABREU, 2005; BARBOSA, 2006). Se a articulação das festas do Divino com esse tipo de agrupamentos musicais (geralmente conhecidas pela designação de folias) é recorrente no Brasil, é exclusiva do Maranhão esta solução de feminização deste desempenho ritual.

A sequência das festas apresenta uma certa regularidade. 0 seu início é assinalado pela abertura da tribuna. Esta é seguida, algum tempo depois, - pelo buscamento e o levantamento do mastro, rituais que decorrem num ambiente de folguedo e excesso que contrasta com a solenidade que caracteriza outros segmentos das festas.

0 dia da festa compreende um conjunto diversificado de rituais. Entre eles destaca-se a ida à missa dos impérios, geralmente seguida de um cortejo. Uma vez de regresso ao recinto da festa, os impérios são sentados na tribuna onde recebem as homenagens das caixeiras e, terminado esse ritual, tem lugar um almoço para os impérios, para as caixeiras e para todos os convidados e outras pessoas que queiram participar nos festejos. Esse almoço é muito concorrido, pode juntar centenas de pessoas, e é um dos segmentos rituais mais dispendiosos e também mais importantes no prestígio e na reputação de uma festa. Durante a tarde, enquanto as caixeiras vão entoando vários cânticos junto à tribuna, tem lugar uma radiola de reggae que pode ser acompanhada pela realização de outras atividades festivas, como o tambor de crioula.

No dia seguinte ao dia da festa, faz-se o derrubamento do mastro que, tal como o seu buscamento e levantamento, decorre num registo de folguedo e excesso. Realiza-se depois o repasse das posses (designação dada aos trajes e outros adereços cerimoniais) entre as crianças dos impérios, acompanhado da sua investidura nos cargos que desempenharão no ano seguinte. Uma vez concluído o repasse das posses, ocorre o encerramento da tribuna, no decurso do qual a festa é dada por terminada e o Espírito Santo - depois de se ter feito presente durante todo o período da festa -, regressa à sua morada divina. Por fım, no dia seguinte, pode realizar-se o carimbó das caixeiras, caracterizado, tal como os segmentos relacionados com o mastro, por uma atmosfera de brincadeira e excesso.

As festas do Divino têm uma articulação privilegiada com o tambor de mina. Assim, de um total de 79 festas existentes em São Luís, 61 - isto é, mais de 2/3 - têm lugar em terreiros de tambor de mina (51) ou de umbanda $(10)^{4}$. Dado que o número estimado de terreiros de tambor de mina em São Luís é de 120, aproximadamente, isto quer dizer que metade deles realiza festas do Divino. Entre esses terreiros estão muitos dos mais importantes de São Luís; deve também ser sublinhado que muitas casas que não realizam a festa promovem de qualquer forma uma salva ao Divino Espírito Santo por ocasião do seu festejo principal ${ }^{5}$.

4. Os dados apresentados resultam da consulta do cadastro das festas do Divino existente no Centro de Cultura Popular Domingos Vieira Filho (LEAL, 2012). Este cadastro serve de base à política de financiamento das festas seguida por esse organismo da Secretaria Estadual da Cultura do Maranhão, que será analisada mais à frente.

5. Esta salva consta da realização de toques de caixa junto ao altar católico da casa ou junto a um pequeno altar erguido expressamente para o Divino. 
A história dessa relação entre festas do Divino e tambor de mina remonta ao século XIX. As primeiras festas de terreiro teriam sido fundadas entre finais do século XIX (na Casa das Minas) e as primeiras décadas do século XX (na Casa de Nagô). Depois, o número de festas em terreiros parece ter continuado a crescer, de tal forma que nos anos 1940 o antropólogo Otávio Eduardo (1948) deu como adquirida a sua realização na maioria dos terreiros que então recenseou.

\section{Gráfico 1 - Décadas de fundação das Festas do Divino}

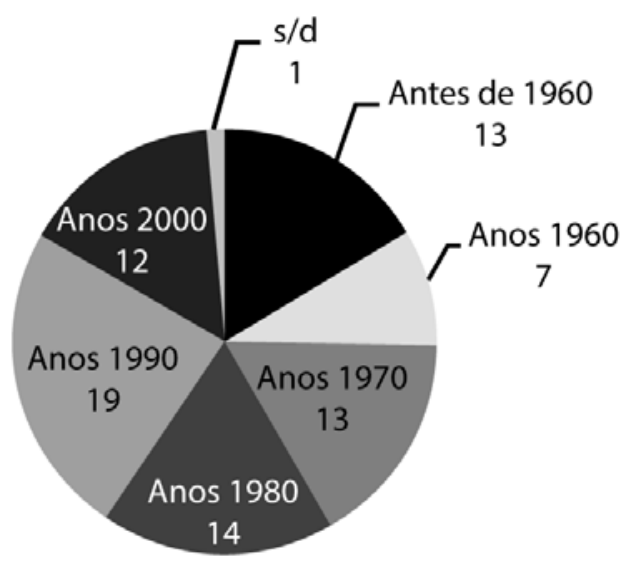

Terá sido, todavia, a partir dos anos 1970 que o número de festas de terreiro conheceu um aumento mais significativo. De facto, das 79 festas atualmente existentes, quarenta foram criadas a partir dessa década. Essa tendência, que prosseguiu nos anos 1980, atingiu o pico nos anos 1990 e prolongou-se pelos anos 2000 (Gráfico 1).

Nos terreiros, as festas do Divino articulam-se de vários modos com o tambor de mina. A sua realização tanto pode resultar de uma promessa ou de uma devoção do pai ou mãe de santo, como do pedido ou, nalguns casos, da devoção de um dos seus encantados, que solicita a realização da festa. Os adultos que bancam os impérios também o fazem tanto em resultado de uma promessa ao Espírito Santo como de um pedido de um encantado. Em consequência, as entidades espirituais do tambor de mina - voduns, orixás, gentis, caboclos, princesas - têm uma presença importante nas festas. Elas podem, por exemplo, associarse à definição de alguns dos seus aspectos organizativos. Muitos segmentos rituais das festas contam também com a presença dessas entidades. Por exemplo, os caboclos, em particular os caboclos farristas, têm uma participação relevante nos segmentos relacionados com o buscamento, o levantamento e o derrubamento do mastro e a receção da coroa e dos impérios. A seguir à missa do dia da festa está geralmente a cargo de um dos principais encantados do pai ou mãe de santo. Em muitas casas, a abertura e o encerramento da tribuna envolvem também a participação de entidades espirituais do tambor de mina.

As festas do Divino fazem, geralmente, parte de um conjunto festivo mais vasto que engloba vários toques em homenagem a entidades espirituais da mina. Esses toques realizam-se diante da tribuna do Divino, que se mantém montada por mais sete dias após o encerramento formal da festa, e prevêem modos variáveis de integração ritual entre tambor de mina e culto ao Espírito Santo. Nalguns casos, o regresso da coroa ao altar da casa é realizado por meio de um ritual que tem lugar no final do último toque de tambor de mina. No decurso de alguns toques podem também ser cantadas doutrinas com referências ao Divino Espírito Santo, e nalgumas casas durante um toque de tambor de mina dedicado especialmente às princesas, as crianças dos impérios sentam-se na tribuna e assistem à parte inicial do ritual. 


\section{Objetificações da cultura}

Caracterizadas pelos traços gerais que passamos em revista, as festas do Divino têm sido objeto de um conjunto de políticas e práticas de objetificação da cultura. Este conceito foi proposto por Richard Handler e visa designar o modo como determinados traços da cultura (dança, arquitetura popular, etc.)

são transformados em coisas discretas que devem ser estudadas, catalogadas e exibidas. Isso envolve seleção e reinterpretação. 0 objetificador olha para um meio que lhe é familiar e descobre que é composto de traços tradicionais, coisas que ele retira de um contexto adquirido e transforma em espécimens típicos (HANDLER, 1988, p. 77).

Com similitudes a abordagens propostas por outros autores - por exemplo, Kirshenblatt-Gimblett (1998) e Carneiro da Cunha (2009) -, as ideias de Handler acerca da objetificação da cultura visam sublinhar o modo como determinados aspetos - fundamentalmente locais - da cultura são transformados em signos identitários usados à escala local regional e/ou nacional por elites intelectuais e políticas.

No caso de São Luís, estas políticas e práticas objetificadoras, que envolveram folcloristas, antropólogos, organismos estaduais, ativistas e associações culturais, inserem-se no quadro mais vasto dos processos de patrimonialização da cultura popular que se desenvolveram no Maranhão, ao longo do século XX. Como sublinhou Antonio Evaldo Barros (2007, p. 17), alguns deles iniciaram-se a partir dos anos 1930. Mas foi sobretudo a partir dos anos 1960 que ganharam uma expressão mais efetiva (ALBERNAZ, 2004; PARODI, 2011). Eles passaram, em primeiro lugar, por um trabalho de tematização etnográfica (e/ou antropológica) das diferentes expressões das culturas populares do Maranhão. Envolveram, em segundo lugar, a adoção de políticas culturais da responsabilidade de organismos estaduais direcionadas à cultura popular. Finalmente, assentaram num conjunto de iniciativas desenvolvidas por ativistas e associações culturais.

$\mathrm{Na}$ tematização etnográfica da cultura popular do Maranhão - em particular no campo dos rituais e dos chamados "folguedos" - é geralmente destacada a importância do trabalho de pesquisa e divulgação de Domingos Vieira Filho. Ligado à Sub-Comissão Maranhense de Folclore entre 1948 e 1950, publicou regularmente sobre o folclore maranhense entre as décadas de 1940 a 1970 (BRAGA, 2000). Em 1980 refundou a Sub-Comissão Maranhense de Folclore - renomeada Comissão Maranhense de Folclore - que se mantém ativa até aos nossos dias. Embora outros autores tivessem acompanhado Domingos Vieira Filho no seu interesse inicial pelas culturas populares do Maranhão, foi sobretudo a partir dos anos 1970 que esse interesse ganhou novos protagonistas. Entre esses protagonistas, para além de Carlos de Lima (1988 [1972]), conta-se sobretudo Sérgio Ferretti, que atuou como uma espécie de braço direito de Domingos Vieira Filho na Comissão Maranhense de Folclore. Antes de ter orientado sua pesquisa para o estudo da Casa das Minas, Ferretti conduziu pesquisas sobre a Dança do Lelê (FERRETTI, 1977) e sobre o Tambor de Crioula (FERRETTI, 2002 [1979]). A partir da morte de Domingos Vieira Filho, em 1982, foi ele que assumiu a direção da Comissão Maranhense de Folclore que, a partir de 1993, iniciou a publicação, que se mantém até hoje, do Boletim da Co- 
missão Maranhense de Folclore. Contando com a colaboração de um diversificado grupo de folcloristas e antropólogos, o Boletim desempenhou um papel de grande importância na expansão e consolidação do trabalho de tematização etnográfica das culturas populares do Maranhão.

Esse trabalho foi acompanhado, a partir da segunda metade dos anos 1960, por um crescente envolvimento de organismos municipais e estaduais na esfera das culturas populares. Como sublinhou António Evaldo Barros, embora com antecedentes em décadas anteriores, foi sobretudo nessa década que esse envolvimento se traduziu - sobretudo a partir dos governos estaduais de José Sarney (1966-1971) -, na "implementação de políticas estatais regionais" (BARROS, 2007. p. 20) dotadas de estabilidade e de meios administrativos e financeiros. Nesse trabalho foi mais uma vez decisiva a figura de Domingos Vieira Filho, que exerceu funções de direção nos principais organismos estaduais criados para dar corpo a essas políticas. Entre 1961 e 1970 foi ele o diretor do Departamento Estadual de Cultura e, entre 1975 e 1979, o Presidente da FUNC, que substituiu esse Departamento. Durante um período mais curto, que teve início em 1962, dirigiu também o organismo estadual responsável pelo turismo, sector que que desde cedo se associou às políticas culturais direcionadas para a cultura popular. Foi graças à sua ação que foi criado em 1971 o Museu (inaugurado em 1982) que hoje leva o seu nome, dedicado exclusivamente às culturas populares do Maranhão. Outra pessoa relevante na implementação de políticas voltadas para a cultura popular foi Zelinda Lima - esposa do folclorista Carlos de Lima - que começou por trabalhar com elas na prefeitura de São Luís e que, a partir dos governos de Sarney, esteve ligada a diversos organismos estaduais orientados para o turismo.

Continuadas ao longo da década de 1980, estas políticas de objetificação da cultura ganharam um novo ímpeto a partir dos anos 1990, por iniciativa dos governos de Roseana Sarney (1995-2002, 2009-2010, 2011-2014). Filha e herdeira política de José Sarney, Roseana Sarney "abraçou e investiu na cultura, elegendo essa área como uma de suas prioridades" (LIMA, 2006, p. 304). Objeto de apreciações contraditórias (e.g. CARDOSO, 2008), este envolvimento dos governos de Roseana Sarney com a cultura popular deu um novo impulso às políticas iniciadas na segunda metade dos anos 1960 e estabilizadas nas décadas seguintes.

Simultaneamente às políticas estaduais que passámos em revista, os processos de objetificação da cultura popular assentaram também - especialmente a partir dos anos 1970 - num conjunto de iniciativas de ativistas e associações culturais, ligadas a propostas artísticas alternativas. Entre essas associações conta-se o Laborarte um laboratório de artes que nasceu em 1972. Inicialmente dirigido por Tácio Borralho, o Laborarte passou a ser dirigido, entre 1978 e 2001, por Nelson Brito e, segundo a antropóloga Lady Selma Albernaz, procurava

produzir novas formas de expressões artísticas que reunissem teatro, música e dança com cultura popular, sendo um grupo marcante, e atuante até hoje em São Luís. (...) 0 objetivo do Laborarte era fazer um trabalho artístico para preencher um vazio ideológico, contrapor-se ao regime militar de 1964 e à censura, portanto um teatro de resistência e contestação. 0 grupo integrava artistas de distintos gêneros de arte, que usavam a 
linguagem da cultura popular (ALBERNAZ, 2004, p. 144) ${ }^{6}$.

Outros grupos foram também importantes. Entre eles conta-se o Grupo do Pai Simão - ativo nos anos 1970 e depois extinto -, e sobretudo a Companhia Barrica (ALBERNAZ, 2004; PARODI, 2011), que se mantém atuante até hoje e que influenciou a criação de outros grupos parafolcóricos, como o Boi Pirilampo. Dando grande relevo ao bumba meu boi,

a Companhia Barrica é um grupo de artistas formado em 1985 (...) que revigora e evidencia a tradição dos folguedos e das festas populares do Maranhão, apresentando em ruas e praças e palcos da vida a diversidade de ritmos e danças peculiares dos festejos juninos e carnavalescos da cultura maranhense (https://pt.wikipedia.org/wiki/ Companhia_Barrica. Acesso em 7 jan. 2018).

É no interior deste quadro que acabei de esboçar, que é possível entender os processos de objetificação cultural das festas do Divino ${ }^{7}$. De facto, embora o lado mais visível, e estudado, desses processos tenha passado pelo bumba meu boi (ALBERNAZ, 2004; NUNES, 2011; PARODI, 2011), eles incidiram também sobre as festas.

Nesses processos podemos distinguir duas fases. A primeira inicia-se nos anos 1950 e consolida-se nos anos 1970. É marcada pela tematização etnográfica das festas, sem que esta dê todavia lugar a desdobramentos relevantes em termos políticos.
A segunda inicia-se nos anos 1980 e caracteriza-se pelo gradual desenvolvimento de iniciativas dinamizadas por ativistas culturais e pela adoção, a partir dos anos 1990, de políticas culturais mais efetivas em relação às festas.

A primeira fase é marcada pelas pesquisas de Domingos Vieira Filho (2005 [1954]; 1982; 1977) e, mais tarde, de Carlos de Lima (1988 [1972]) sobre as festas. Recebeu depois um novo ímpeto, a partir do final dos anos 1980, com os trabalhos de Sérgio Ferretti e de outros antropólogos. Por seu intermédio, as festas do Divino passaram a ser vistas - em conjunto com outras manifestações culturais - como expressões da cultura e da identidade do Maranhão. Algumas linhas de força destacam-se nessas tematizações. A primeira prende-se com a importância atribuída às festas do Divino de Alcântara, encaradas como uma espécie de modelo originário - e o "mais autêntico" - das festas do Divino em todo o estado. Os escritos de Carlos de Lima (1988 [1972]) foram particularmente importantes a esse respeito, mas deve ser também destacado o trabalho de Pedro Braga Santos (1980). A segunda linha de força tem que ver com a valorização das origens portuguesas e, mais especificamente, açorianas, das festas do Divino. Este é um tema que aparece desde cedo nos escritos de Domingos Vieira Filho, que sublinhou as origens portuguesas das festas (VIEIRA FILHO, 1977), mas que, a partir de 2002, será reformatado por Carlos de Lima (2002a; 2002b) que defenderá as origens mais especificamente açorianas do

6. Sobre o Laborarte ver também Parodi (2011, p. 178-186).

7. Para a elaboração deste quadro genérico sobre processos de patrimonialização da cultura popular no Maranhão, apoiei-me nos estudos de Ana Socorro Braga (2000) Lady Selma Albernaz (2004) António Evaldo Barros (2007) e Michele Parodi (2011). Ai poderão ser encontrados os detalhes de processos que acabei de resumir de uma forma necessariamente simplificadora. 
culto do Divino no Maranhão ${ }^{8}$. Outra linha de força na tematização das festas do Divino é mais tardia e passou pela identificação das caixeiras - e da "música do Divino" como um dos principais motivos de singularidade das festas (PACHECO; GOUVEIA; ABREU, 2005; BARBOSA, 2006). Uma última linha de força assentou na tematização das articulações entre as festas e os terreiros de tambor de mina. Esse era ainda um tópico ausente dos trabalhos de Domingos Vieira Filho e de Carlos de Lima, mas a partir do final dos anos 1980, sobretudo por intermédio das pesquisas de Sérgio Ferretti (1995, 1999), passou a assumir um papel de maior relevo na argumentação culturalista da importância das festas.

Uma vez iniciado, este processo de tematização etnográfica não se traduziu imediatamente em políticas culturais efetivas - ao contrário do que sucedeu com o bumba meu boi. É certo que, a partir dos anos 1980, com a inauguração do museu do Centro de Cultura Popular Domingos Vieira Filho, as festas do Divino, em conjunto com o bumba meu boi e com o tambor de mina, foram integradas na narrativa museológica autorizada sobre as particularidades das culturas populares do Maranhão. Mas passos mais decisivos no sentido do transporte da erudição etnográfica e/ou antropológica para a esfera das políticas culturais tiveram que esperar pelos anos 1990.

Foi a partir dessa década que tomou corpo e se desenvolveu uma política sistemáti- ca, definida e dirigida por organismos culturais estaduais, de apoio às festas do Divino. Esta assentou em dois pilares principais: a implementação de um programa de apoio financeiro às festas e a organização de eventos e programas de ação orientados para a sua visibilização no espaço público.

A implementação dos apoios financeiros remonta ao final dos anos 1980 (ou ao início dos anos 1990) e teve inicialmente um âmbito limitado, uma vez que contemplava exclusivamente a festa do Divino de Alcântara. Posteriormente, alargou-se e passou a englobar outras festas. Numa fase inicial, esse alargamento parece ter sido seletivo, beneficiando sobretudo as casas de tambor de mina de São Luís mais antigas e prestigiadas: a Casa das Minas e a Casa de Nagô. No entanto, no decurso dos anos 1990 e dos anos 2000, outras festas foram englobadas pelos financiamentos estaduais ${ }^{9}$. Em consequência, em 2014, perto de 200 festas em todo o estado, 79 das quais em São Luís, eram apoiadas pela Secretaria Estadual da Cultura. Esses apoios eram variáveis, e se nalguns casos podiam atingir valores mais significativos, noutros casos não iam além de $\mathrm{R} \$ 500,00$ por festa.

Quanto à organização de eventos, tem envolvido um conjunto de iniciativas, geralmente promovidas pelo Centro de Cultura Popular Domingos Vieira Filho, centradas no culto do Divino Espírito Santo. Algumas dessas iniciativas decorrem no quadro do Projeto Divino Maranhão. Embora se tenha

8. Para um tratamento mais detalhado das narrativas de origem das festas do Divino no Maranhão, ver Leal (2017, p. 234-246).

9. A Casa Fanti-Ashanti, a Casa de Iemanjá e o terreiro Jardim da Encantaria terão sido, segundo Pai Clemente Filho (pai de santo do terreiro Jardim da Encantaria), as primeiras beneficiárias desse alargamento, que depois se foi estendendo a outros terreiros. A breve síntese histórica dos apoios financeiros às festas do Divino que apresentei baseia-se na consulta ao arquivo dos convites para as festas existente no Centro de Cultura Popular Domingos Vieira Filho. 0 carácter lacunar do arquivo apenas possibilita a indicação de algumas tendências gerais. 
mantido até hoje, este projeto foi particularmente importante nas décadas de 1990 e 2000 e constava de um conjunto de eventos que se realizavam geralmente em maio. Esses eventos envolviam desde a montagem de uma tribuna do Divino no Centro de Cultura Popular Domingos Vieira Filho até à organização de cortejos alusivos às festas, que percorriam o centro da cidade e integravam grupos de caixeiras e impérios de várias festas do Divino (PARODI, 2011). Simultaneamente, generalizaram-se iniciativas como a organização regular de ofıcinas de caixa, espetáculos com grupos de caixeiras ou o lançamento de livros e CDs centrados na música do Divino. A presença de grupos de caixeiras em eventos culturais fora de São Luís também se tornou importante.

$\mathrm{Na}$ adoção dessas políticas, foi crucial o papel de Maria Michol Carvalho que, depois de ter assegurado vários cargos de assessora na Secretaria Estadual da Cultura, esteve à frente do Centro de Cultura Popular Domingos Vieira Filho entre 1996 e 2009. Falecida em 2012, Maria Michol Carvalho desenvolveu um trabalho relevante de pesquisa - a sua dissertação de mestrado incidiu sobre o bumba meu boi (CARVALHO, 1988) -, foi presidente da Comissão Maranhense de Folclore, teve um papel central na organização - em São Luís - do X Congresso Brasileiro de Folclore. Publicou também sobre festas do Divino (CARVALHO, 2010a; 2010b), e quando faleceu trabalhava numa tese de doutoramento sobre as festas. Mas era sobretudo, como escreveu Sérgio Ferretti (2012b. p. 20), "uma pessoa de ação" que, para além do papel central que teve na implementação de políticas de estímulo e apoio á cultura popular, as abriu para as festas do Divino.

A par dessas políticas desenvolvidas a partir de cima, tiveram também lugar, a partir dos anos 1980, processos de objetificação cultural das festas conduzidos por ativistas e associações culturais. Entre essas associações, ocupa mais uma vez lugar de relevo o Laborarte. De facto, no trabalho desenvolvido por este grupo as festas do Divino tiveram um lugar importante, sobretudo a partir do momento que Dona Teté - falecida, mas que durante muito tempo foi uma figura destacada na cena cultural de São Luís -, começou a trabalhar com ele. Segundo Rosa Reis, uma consagrada artista local e atual diretora do Laborarte,

quando ela [Dona Teté] veio pra cá trabalhar no Laborarte, em 1980 (...) ela começou a trabalhar com a gente com a festa do Divino, ela era caixeira também do Divino, caixeira, rezadeira. E ela começou por ensinar o toque de caixa pro espetáculo que ia acontecer aqui no Laborarte.

Foi a partir dessa primeira experiência que Dona Teté criou, em 1986, um grupo de cacuriá, com uma ligação também forte à "música do Divino":

Desde quando Dona Teté estava aqui ela sempre falava pra gente conversando que o cacuriá tem toda essa história, a partir da festa do Divino Espírito Santo, que é no final da festa, quando depois da derrubada do mastro, as caixeiras vão serrar o mastro, e tem todas aquelas musiquinhas, né? serra, serra, serrador, siriri, e tem aquela brincadeira, que a gente vê na Casa das Minas. Então, as músicas do cacuriá (...) tem essa raiz na festa do Divino Espírito Santo no carimbó de caixeiras, tanto que as músicas, as letras das músicas, a melodia, tudo você vai ver vem do carimbó.

A partir do exemplo do Laborarte, foram criados vários outros grupos de cacuriá em 
São Luís. Quanto ao Laborarte - para além do seu próprio grupo - continua assumindo outras iniciativas relacionadas com o Divino, como a organização de espetáculos e a realização regular de oficinas de caixa. Simultaneamente, Rosa Reis mantém uma ligação forte com a música do Divino. Para além de tocar caixa na festa do Divino da Casa das Minas, incorporou também referências à música do Divino no seu repertório musical.

É neste quadro, de crescente visibilidade das festas do Divino nos discursos e práticas sobre cultura popular do Maranhão, que é possível entender a realização, em 2006 e em 2007, de dois grandes eventos relacionados com as festas do Divino, em cuja organização Ester Marques - professora da UFMA com uma ligação forte às políticas culturais do estado -, desempenhou um papel de relevo ${ }^{10} .0$ primeiro evento foi o I Encontro Luso-Maranhense sobre a Memória Açoriana do Estado. Realizado no âmbito da UFMA e contando com o apoio do governo estadual, o Encontro resultou de contactos estabelecidos entre o Governo Regional dos Açores e ativistas culturais maranhenses com destaque para Ester Marques -, e visava resgatar a memória da colonização açoriana do estado. Tendo contado com a participação de uma numerosa delegação dos Açores, o Encontro deu grande relevo às festas do Divino. Além de conferências sobre o tema - designadamente de Carlos de Lima, Fátima Sopas Rocha e do Padre Hélder Fonseca
Mendes (este último dos Açores) -, a programação incluiu a apresentação de um grupo de caixeiras do Divino e a participação dos conferencistas e convidados na festa do Divino de Alcântara ${ }^{11}$.

Posteriormente, o Governo dos Açores não mostrou interesse no prolongamento da colaboração iniciada em 2006 (LEAL, 2017), mas isso não impediu que Ester Marques viesse a organizar em 2007 um novo evento, desta vez centrado exclusivamente nas festas do Divino. Promovido no âmbito do SESC, o evento intitulado "O Divino, Ontem, Hoje e Amanhã” incluiu um vasto leque de atividades: conferências, debates, exposições, atuações de grupos de caixeiras, visitas a terreiros, assistência a cerimônias relacionadas com a festa do Divino na Casa das Minas e na Casa de Nagô, etc. Entre os conferencistas convidados estavam Sérgio Ferretti, Carlos de Lima, Michol Carvalho, Ananias Martins, mas também pessoas ligadas a terreiros, tais como: Pai Euclides (falecido, pai de santo da Casa Fanti-Ashanti); Pai José Itaparandi (que dirige o terreiro da Pedra Encantada); Celeste Santos (também já falecida, foi responsável pela festa do Divino na Casa das Minas); Sebastião Cardoso (ligado à Casa de Nagô e à Casa de Iemanjá). Embora o governo do Açores se tivesse alheado da iniciativa, esta contou de novo com a presença do Padre Hélder Fonseca Mendes assim como de ativistas culturais ligados às festas do Espírito Santo entre a diáspora açoriana na América do Norte.

10. A informação sobre estes dois eventos foi-me transmitida pela própria Ester Marques, em entrevista realizada em 2011. A entrevista foi complementada com cópias dos dossiês relativos aos dois eventos, que fazem parte do seu arquivo pessoal.

11. Fátima Sopas Rocha é uma professora da UFMA cuja pesquisa tem incidido sobre as festas do Divino (ROCHA, 2010). Quanto ao Padre Hélder Fonseca Mendes, foi vigário geral da diocese dos Açores e é também o autor de um livro - de cunho teológico e pastoral - sobre as festas do Espírito Santo, com particular ênfase nos Açores (MENDES, 2006). 
A importância desses dois eventos deve ser sublinhada. Tendo sido promovidos num período em que já estavam implantadas as políticas estaduais de apoio às festas do Divino, eles foram centrais para o processo de culturalização das festas. Por um lado, por intermédio de conferências e debates, deram grande visibilidade a tematizações etnográficas sobre as festas disponíveis desde os anos 1950, mas até então circunscritas a artigos e livros que não tinham necessariamente uma circulação ampliada. Por outro lado, o facto de ambos os eventos, particularmente o evento de 2007, se basearem numa lógica de interface entre eruditos e pessoas ligadas diretamente às festas - pais de santo, caixeiras, etc. - garantiu uma maior eficácia a esse processo de circulação ampliada das narrativas etnográficas sobre as festas. Ideias como a origem açoriana das festas, a importância das caixeiras e da música do Divino como fator da sua individualização em São Luís, ou a relação - também ela exclusiva de São Luís - entre festas do Divino e terreiros de tambor de mina, puderam assim reforçar o seu peso na tematização das festas. 0 facto de as duas iniciativas terem contado com a participação de oradores de origem açoriana ou portuguesa foi também importante para a legitimação da importância cultural das festas: não era mais só a partir de dentro (e do seu presente), mas também a partir de fora (e das suas raízes), que as festas do Divino de São Luís eram "prestigiadas”.

Em resumo: tanto por intermédio de políticas implementadas a nível estadual, como a partir de iniciativas promovidas por ativistas culturais, desenvolveu-se a partir dos anos 1990 um conjunto de processos de objetificação das festas do Divino que ajudaram a tornar visível o seu valor cultural e identitário. Como foi referido ante- riormente, esses processos não colocaram as festas no mesmo patamar em que se encontra por exemplo o bumba meu boi, mas incluíram-nas no pacote cultural por intermédio do qual se torna possível discursar a identidade cultural do Maranhão. As festas do Divino, que já eram cultura (sem aspas), passaram assim a tornar-se "cultura" (com aspas) (CUNHA, 2009). Passaram dessa forma a integrar o "regime patrimonial" (HAFSTEIN, 2007) vigente em São Luís.

\section{Os impactos da culturalização}

Como referi anteriormente, os anos 1990 e 2000 foram marcados por uma expansão signifıcativa no número de festas do Divino de terreiro: 19 novas festas foram criadas na década de 1990 e 12 na década de 2000. Isto é, do total de 79 festas existentes em 2009 em São Luís, cerca de 1/3 foi criada nessas duas décadas (Gráfico 1).

Para muitas pessoas, essa expansão decorre diretamente da adoção das políticas e práticas de objetificação das festas que passei em revista. Os impactos destas são, entretanto, objeto de avaliações contraditórias. Algumas pessoas, na sua grande maioria exteriores aos terreiros, adotam a esse respeito uma interpretação utilitarista, centrada na importância do "dinheiro da cultura” na expansão recente das festas. Como me disse uma delas, foi com "o dinheiro da cultura" que "começou esse bando de festas surgindo, porque o povo achava que era muito dinheiro".

A maioria dos pais e mães de santo, todavia, não se reconhece nesta interpretação e sublinha o contributo marginal desse dinheiro para as despesas da festa. De acordo com Pai Wender (pai de santo da casa Ilê Ashé Obá Izô), “eu tenho certeza que não é por esse dinheiro, que esse dinheiro mal dá 
pra fazer meia hora da festa (...). Quem fala isso, nunca fez uma festa do Divino. Que, se fizesse ia ver que não tem porquê fazer por fazer”. Também para Pai Euclides muita gente "diz que é por causa do dinheiro que a cultura dá. 0 dinheiro que a cultura dá, não dá pra bancar uma festa, já ajuda, mas não dá pra bancar uma festa desse porte”. Pai Edmilson - pai de santo da Tenda Umbandista Santo Onofre (Igaraú) - é ainda mais categórico: "o dinheiro que vem (...) nem dá pra gente fazer o almoço da festa! (...) Minha gente, é loucura, quem [é que] tá botando festa por causa da cultura? É loucura! Eu vou-lhe dizer: eu, quando eu comecei, eu comecei sem a cultura!"

0 modo enfático como muitos pais de santo sublinham o carácter marginal do "dinheiro da cultura" na expansão recente das festas do Divino de terreiro deve ser levada em linha de conta. Até pode ser que nalguns casos a expectativa desse dinheiro tenha facilitado a cooptação das festas. Por um lado, muitos dos terreiros que recebem apoios financeiros mais robustos já realizavam as festas do Divino antes da implementação das políticas de apoio financeiro às festas. E, por outro lado, a maioria dos terreiros, entre os quais aqueles que começaram a realizar as festas nos anos 1990 e 2000, recebe um apoio financeiro muito limitado, situado, como vimos, na faixa dos $\mathrm{R} \$ 500,00$. Esse dinheiro pode, eventualmente, contribuir para uma maior largueza de gastos, mas é uma contribuição marginal para as despesas - geralmente situadas entre os $\mathrm{R} \$ 10.000$ e os $\mathrm{R} \$ 15.000$ - envolvidas nas festas do Divino.

Isto não quer dizer, todavia, que a atribuição de subsídios por organismos culturais estaduais, combinada com outras políticas de objetificação cultural, não tenha impactado nas festas de terreiro e não tenha tido importância na sua expansão recente. Examinada mais de perto, a expressão “dinheiro da cultura" fornece um bom ponto de partida para a análise desses impactos. De facto, nas explicações utilitaristas prevalecentes entre pessoas exteriores aos terreiros, o acento é colocado no facto do "dinheiro [da cultura]" ser "dinheiro". Para os pais e mães de santo e outras pessoas mais diretamente envolvidas com a realização das festas, esse "dinheiro" também é "dinheiro", mas é sobretudo "[dinheiro] da cultura”. 0 que importa é o facto de ele traduzir, em conjunto com as restantes políticas e práticas de objetificação adotadas por organismos estaduais ou por ativistas culturais, um reconhecimento do valor cultural das festas.

Foi justamente esse reconhecimento que impactou nos terreiros. Ele acrescentou uma nova dimensão a festas que já se realizavam há muitos anos e eventualmente favoreceu a adoção das festas por outros terreiros. Por seu intermédio, as festas viram acrescentadas aos valores - religiosos, sociais - que já eram seus, uma mais-valia cultural.

Essa culturalização das festas teve impactos diferenciados. Nalguns terreiros que estudei, ela assumia formas mais difusas, traduzidas na ideia genérica que as festas do Divino seriam - a par de outras manifestações culturais, com destaque para o bumba meu boi - uma das expressões das culturas populares negras de São Luís ou, de uma forma mais geral, da identidade cultural do Maranhão. A expressão mais usada a esse respeito era "tradição": as festas seriam uma "tradição", reconhecida como tal pelos organismos estaduais, por ativistas culturais e pela sociedade em geral. A consciência de que os terreiros eram os principais depositários dessa "tradição" era também generalizada. Quanto à expres- 
são "cultura" era usada num sentido mais preciso e aplicava-se sobretudo ao reconhecimento do valor cultural das festas pelos organismos estaduais.

Esta tematização mais difusa das festas como "tradição" é partilhada por muitos promesseiros do Divino - designadamente por aqueles que bancam os impérios - e por muitas pessoas que frequentam as festas. Para elas, também as festas situam-se na esfera das práticas e expressões culturais ligadas a ideias genéricas sobre "raízes", "tradição" e "identidade" no Maranhão.

A par dessas expressões mais difusas, o impacto do discurso culturalista sobre as festas nos terreiros apresenta também expressões mais precisas, sobretudo naqueles que são dirigidos por pais e mães de santo letrados.

Uma delas passa pela cooptação do discurso culturalista nos convites - geralmente folders em formato A5 - que visam assegurar a divulgação das festas e a captação de donativos para a sua realização. Se em muitos casos, os convites contêm apenas a programação das festas, nalguns casos passaram a integrar pequenos textos introdutórios, que põem justamente em relevo a dimensão "cultural" das festas. É o que faz a casa Ilê Ashé Obá Izô, que, pelo menos desde 2012, divulga a festa do Divino através de um folder em que ocupa lugar de destaque o seguinte texto:

A homenagem ao Divino Espírito Santo é grande referência na cultura popular, tendo destaque no Maranhão, Nela, se preserva a tradição de cultuar as entidades católicas e as homenagens aos grandes impérios europeus. No Maranhão, as homenagens ao Divino Espírito Santo ocorrem desde o século XVII, período que culminou na inserção dos açorianos no Maranhão. Tais celebrações tornaram-se importantes no cenário cultural maranhense e importante mecanismo de resistência, reprodução social e valorização das mulheres, pois são as chamadas Cacheiras do Divino que conduzem a festa mostrando traços de liderança e da importância das mulheres nas casas de culto afro-tradicional [os itálicos são meus].

0 que há a relevar nesse texto é, por um lado, o recurso à expressão "cultura" (ou "cultural") como forma de definição das festas e, por outro lado, o modo como essa culturalização das festas é respaldada por dois argumentos principais: a antiguidade das festas, que no Maranhão remontariam ao século XVII e à colonização açoriana do estado, e a importância da música do Divino - objeto de uma interpretação que a coloca no universo "afro-tradicional".

Estes argumentos são usados frequentemente por outros pais e mães de santo. 0 argumento da antiguidade das festas, sob a forma de uma narrativa de origem mais ou menos partilhada, é particularmente importante no modo como as festas de terreiro de hoje são vistas, isto é como a continuação de uma tradição enraizada na longa duração prestigiada da história e da cultura do Maranhão e das suas raízes, simultaneamente europeias e africanas.

Por exemplo, para Pai Clemente Filho, pai de santo do terreiro Jardim da Encantaria, a festa do Divino

É uma promessa que foi da rainha Isabel, de Portugal. Devido a uma enfermidade que o marido dela teve (...) ela se pegou com Espírito Santo. Que se ele ficasse bom, ela fazia a [festa]. Então ela montou uma festa do Divino como se fosse a corte que existia (...) lá na época. E ai ela veio pra cá. (...) Uns dizem que os negros fizeram um protesto em Alcântara 
(...). Então eles vestiram negros de [reis]. Formaram uma corte, e fizeram a festa.

Já a versão do mito de origem das festas contada por Pai Euclides é mais longa:

0 que eu sei do passado, por pessoas antigas (...) é que a festa do Espírito Santo (...), dizem que começou em Portugal, através da D. Isabel de Aragão. Por algum motivo, ela fez a promessa com o Divino Espírito Santo e achou que deveria no dia de Pentecostes dar comida aos pobres, aquelas pessoas que trabalhavam em agricultura, plantio, de coisas de alimento, de feijão e milho (...). Então ela achou por bem fazer essa graça pro povo, pra dar essas esmolas e tudo. (...) Então ela começou a fazer essa festa, (...) e por sinal dizem que foi ela que mandou construir a Igreja do Divino Espírito Santo na cidade de Alenquer, isto em Portugal. (...) Então, de lá, a festa veio com os portugueses. Dizem que alguns portugueses que saíram da cidade, de Lisboa, (...) muitos deles que eram oficiais, eu não lembro assim do nome, mas eram pessoas de posses e tudo, porque eram lá do palácio de Belém, do castelo de Belém, da Torre de Belém (...). Esse pessoal, eles tinham vindo com um povo que era açoriano e os açorianos então vieram juntos trazendo esse folguedo para o Brasil. E aqui no Brasil eles se espalharam. Cada um ficou com um lugar e povoou vários estados brasileiros. Esses que ficaram em Alcântara encontraram já lá uma quantidade de negros e os negros que lá estavam começaram a se interessar por aquele tipo de folguedo, de diversão, e terminaram tomando de conta. Porque depois os portugueses morreram, outros retornaram (...) e ficou aquela turma dando continuidade na festa do Divino Espírito Santo.
Portanto, tal como nos modos de tematização erudita das festas que se iniciam nos anos 1950, a culturalização das festas pelos terreiros faz-se também por intermédio do seu enraizamento na longa duração de uma tradição que testemunha da sua importância histórica e cultural.

Quanto à música do Divino, ela surge também em muitos terreiros como um dos registos onde é argumentada a importância “cultural” das festas do Divino. É o que se passa com a Casa de Iemanjá, que tem organizado regularmente oficinas de caixa, associando-se assim diretamente às políticas de objetificação da música do Divino, estimuladas pela “cultura” e por ativistas culturais. Mas é na Casa Fanti-Ashanti que os processos de emblematização da música do Divino são mais importantes. Este terreiro, diferentemente do que se passa com a esmagadora maioria dos terreiros de tambor de mina de São Luís, que recorrem a grupos de caixeiras que circulam por diferentes festas, tem o seu próprio grupo de caixeiras, que era dirigido até 2014 por Dona Kabeca (que, depois do falecimento de Pai Euclides, se tornou na mãe de santo do terreiro). 0 grupo participa regularmente nalgumas apresentações públicas de caixeiras e gravou dois CDs, numa coprodução com a associação cultural Cachuera, baseada em São Paulo. 0 segundo desses CDs foi lançado no Centro de Cultura Popular Domingos Vieira Filho em 2011. No folder de divulgação deste CD a casa Fanti Ashanti era apresentada como "guardiã de muitas manifestações da cultura maranhense [os itálicos são meus]" e a tematização culturalista das festas ocupava um lugar de relevo:

A Festa do Divino Espírito Santo é uma antiga tradição luso-brasileira do catolicismo popular. No Maranhão (...) é uma das mais 
importantes manifestações culturais e religiosas do estado, mobilizando milhares de devotos. Este festejo chegou ao Maranhão no início do século XVIII na cidade de Alcântara e de lá se espalhou por todo o estado [os itálicos são meus].

0 trabalho conjunto da Casa Fanti Ashanti com a associação Cachuera estende-se a outras atividades centradas nas festas do Divino e dele nasceu, nomeadamente, a promoção regular da festa em São Paulo, com a colaboração destacada de familiares de Pai Euclides aí residentes.

É também corrente entre muitos pais e mães de santo, o reconhecimento da importância da atividade de Michol Carvalho na divulgação e valorização das festas do Divino. Para Pai Clemente Filho, por exemplo,

A Michol foi a grande (...) idealizadora, ela foi a que lutou e trouxe esse incentivo né? (...) Ela fazia a abertura, com tribuna armada, no centro de cultura, nas praças, ela fazia cortejos, ela fazia salva lá na casa do Divino lá naquele prédio, tinha várias [iniciativas]. É o mês todinho de Maio, né? Tudo isso ela fazia e tinha esse cachê.

De igual modo são muitos os pais e mães de santo que se recordam dos eventos organizados por Ester Marques e do modo como, por seu intermédio, tomaram conhecimento da narrativa açorianista sobre as origens das festas.

Em certos casos, o discurso culturalista que rodeia as festas assume expressões ainda mais evidentes, como na Casa das Minas e na Casa de Nagô. Estas duas casas de tambor de mina são as casas mais emblemáticas e mais antigas de São Luís. Todavia, ambas se encontram num estado de declínio que parece ser irreversível e que o antropólogo Sérgio Ferretti classificou com recurso à expressão "suicídio cultural" (Ferretti 2012b). 0 número de dançantes é residual, não se realizam iniciações e muitos dos rituais do tambor de mina já não têm lugar. Em consequência, a atividade das duas casas está hoje muito centrada na realização de rituais católicos, com destaque para a festa do Divino, que assumiram entretanto um valor cultural. Como escreve Ferretti,
constata-se uma tendência da realização de festas da cultura popular nestas duas Casas tradicionais que talvez se transformem nu- ma espécie de centro ou de polo de cultura popular. Aproveita-se o prestígio das Casas antigas e o local torna-se um polo de atra- ção cultural, pois costuma receber visitas de pessoas de fora que querem conhecer o lu- gar. Autoridades locais acabam dando algum apoio aos organizadores destas manifesta- ções (2012b, p. 8).

Presente em plano de relevo, no modo como muitos pais e mães de santo tematizam as festas do Divino, a culturalização das festas é também muito forte entre as caixeiras. Envolvidas nas festas de terreiro, elas estão também diretamente envolvidas nas iniciativas - oficinas de caixa, participação em espetáculos em São Luís e fora de São Luís -, por intermédio das quais é sublinhada a dimensão cultural das festas e, em particular, a importância da sua música. Para muitas delas, principalmente para as caixeiras régias Dona Luzia e Dona Jaci, são elas - e não tanto os terreiros - as verdadeiras guardiãs das festas; e a culturalização recente das festas deve-se sobretudo à música que comanda as festas, de que elas são as especialistas e sem a qual as festas não se poderiam realizar. 


\section{Considerações finais: as festas como cultura?}

Em resumo, as políticas e práticas de objetificação das festas do Divino tiveram como principal efeito acrescentar uma dimensão cultural, sancionada pelas políticas estaduais e pelo interesse de ativistas e associações, às festas que têm lugar nos terreiros.

Os termos exatos dessa culturalização merecem alguns comentários adicionais. De facto, uma parte da literatura antropológica sobre os impactos dos processos de objetificação da cultura tem sublinhado o seu carácter transformador. Depois de objetificadas, as expressões e práticas culturais seriam ressignificadas. A sua inscrição no regime patrimonial mudaria a sua natureza. É esse, desde logo, um dos argumentos principais de Richard Handler no seu estudo sobre os processos de objetificação nacionalista da cultura popular do Québec (1988), quando mostra que estes retroagiram sobre o modo como as comunidades passaram a representar e a praticar expressões objetifıcadas da sua cultura. Como escreve Handler, "paradoxalmente, a tentativa de preservar tradições através da sua objetificação produz mudança” (1988, p. 77). Um argumento idêntico foi desenvolvido por Barbara KirshenblattGimblett (1995; 1998), através da sua definição do patrimônio como "segunda vida". Segundo a autora, o patrimônio poderia ser visto como um modo de produção cultural que dá às expressões culturais patrimonalizadas uma segunda vida como "exibição de si mesmas" (KIRSHENBLATT-GIMBLETT, 1995, p. 370), distinta da "primeira vida" que elas tinham previamente à sua objetificação.

Este argumento transformador tem também inspirado alguns estudos sobre festas e rituais, como é o caso, por exemplo, da pesquisa que David Guss (2000) consagrou à festa de San Juan em Curiepe (Venezuela) ou do estudo de Paulo Raposo (2011) sobre festas de mascarados no norte de Portugal. No primeiro caso, Guss mostra como a festa de San Juan deixou de ser "uma celebração intima, organizada por indivíduos devotos que pagavam as suas promessas a um santo milagreiro" para se transformar, num primeiro momento, em um "evento público organizado pela comunidade e aberto a todos" (GUSS, 2000, p. 37) e, num segundo momento, se transformar em um espetáculo turístico que acabou por afastar a própria população local, que começou a passar o período da festa "abrigada em suas casas” (GUSS, 2000). Quanto a Paulo Raposo, mostrou como os processos de objetificação e turistificação das festas de mascarados no norte de Portugal estão associadas a processos através dos quais "a 'cultura local' é simultaneamente inventada, modificada, e revitalizada para os turistas e para os mídia, mas também para as próprias comunidades" (RAPOSO, 2011, p. 135).

Este tipo de argumentação recebeu um novo influxo com o crescimento recente da literatura antropológica sobre patrimônio cultural imaterial. Para Valdimar Hafstein, por exemplo, as políticas de patrimônio cultural imaterial desenvolvidas pela Unesco (ou à sombra da Unesco)

são sobre a mudança - [essas políticas] intervêm nos processos sociais para os modificar (...). 0 património cultural imaterial - como conceito e como instrumento de mudança transforma o modo como as comunidades se relacionam com as suas práticas, incorporando-as no regime patrimonial. E em última instância, o património cultual imaterial também transforma as próprias comunidades (HAFSTEIN, 2007, p. 81). 
No caso de São Luís, os argumentos transformadores foram sobretudo retomados a propósito do bumba meu boi. 0 dossiê de candidatura deste ritual a patrimônio cultural do Brasil, elaborada por Izaurina Nunes, sublinhou algumas dessas transformações, decorrentes da espectacularização da brincadeira resultante das políticas estaduais e municipais orientadas para a sua patrimonialização e turistificação. Entre essas transformações contam-se: a crescente proliferação de bumbas meu boi de sotaque de orquestra, supostamente mais apelativo, em detrimento de brincadeiras de outros sotaques; o recuo de aspetos tradicionais do bumba meu boi como as comédias ou o auto de Mãe Catarina e de Pai Francisco; e a tendência para a esteticização generalizada da maioria dos bois (NUNES, 2011). Isto é, neste caso, tal como no caso da festa de San Juan estudada por David Guss, a objetificação não só fez entrar o bumba meu boi pela porta grande do regime patrimonial e da turistificação, como essa entrada teve efeitos na própria estruturação do script da brincadeira.

Esse tipo de argumentação não parece, todavia, aplicável aos impactos dos processos de objetificação das festas do Divino realizadas em terreiros de tambor de mina. Retomando a terminologia proposta por Barbara Kirshenblatt-Gimblett, a culturalização das festas do Divino abriu certamente uma segunda vida - culturalizada - às festas do Divino de terreiro, mas esta segunda vida não se substituiu à sua primeira vida, isto é, não colocou em causa as principais dimensões que continuam a caracterizar as festas.

Essas dimensões são, antes de tudo, religiosas. Pai Wender, por exemplo, ao mesmo tempo que reconhece o valor cultural das festas, dizia-me que tem algum [motivo mais forte]. Fé, devoção, algum pedido do Divino ali à mistura. [Ou] obrigação da casa (...), alguma entidade que pediu (...) alguma coisa relacionada a isso (...). Então, creio eu que ninguém ia fazer uma festa (...) dentro dessas questões que eles levantaram aí fora. Creio eu que seja por devoção e amor do Espírito Santo ou da (...) entidade que pediu essa festa.

De facto, o motor principal para a realização das festas do Divino continua a ter que ver com motivos onde se cruzam a devoção católica e a obrigação afro-religiosa. É porque as pessoas - pais e mães de santo, filhos e filhas de santo, promesseiros ou simples devotos - querem garantir a ajuda do Divino Espírito Santo ou pretendem satisfazer o pedido, ou a devoção, de algum encantado que as festas têm lugar. Nesse sentido, as festas são, antes de tudo, uma peça importante do sistema de trocas simbólicas que liga os homens e as mulheres aos deuses e aos encantados.

Para além desta sua dimensão religiosa reiteradamente explorada na literatura sobre as festas de terreiro (FERRETI, 1995; LEAL, 2017), as festas do Divino têm também uma importante dimensão social. Elas são a "festa maior dos terreiros", isto é, a festa que mais abre os terreiros de tambor de mina para fora do seu círculo de frequentadores habituais, conectando-os com redes sociais mais alargadas e projetando -os na esfera pública (LEAL, 2014; 2017). Ao seu valor religioso soma-se nessa medida um valor social, estreitamente associado ao modo como elas são instrumentais na visibilização do tambor de mina.

Aquilo que a culturalização faz é acrescentar a essas duas dimensões das festas uma dimensão suplementar, de natureza “cultural”. Essa dimensão deve ser vista 
como uma adição e não como uma substituição (ou como uma secundarização) de algo que já estava lá antes e que continua a estar depois.

Os termos dessa adição devem ser também sublinhados. Ela não se traduziu, como acontece em muitos dos casos estudados pela literatura antropológica, em qualquer alteração ao script ritual das festas. A frequência turística das festas é também irrelevante. Por outro lado, a adição dessa maisvalia cultural inscreve-se numa lógica de abertura que já estava previamente inscrita nas festas do Divino de terreiro. Essa abertura era, e continua a ser, religiosa, operando em direção ao catolicismo. Mas era, e continua a ser, social, uma vez que as festas conectam os terreiros com círculos sociais mais amplos e projetam-nos na esfera pública. Com a culturalização das festas, essa abertura passou também a fazer-se em direção aos discursos e práticas sobre cultura e patrimônio no Maranhão. Nesse sentido, os impactos da culturalização das festas do Divino podem ser definidos não tanto como transformativos, mas como supletivos. Não transformam conteúdos pré-existentes em novos conteúdos, mas suplementam os velhos conteúdos, que continuam a ser determinantes, como um novo conteúdo que acrescenta valor "cultural" às festas.

Embora tenham esse carácter supletivo, os impactos da objetificação cultural das festas, ao encostarem os terreiros às práticas e discursos sobre cultura e patrimônio, devem ser vistos no quadro da tendência mais geral para a inscrição das religiões afro-brasileiras no regime patrimonial. Efetivamente, como sublinharam os antropólogos Jocélio Teles dos Santos (2005) e Roger Sansi (2007), a linguagem do patrimônio tornou-se importante para negociar as condições de inserção e visibilidade das religiões afro-brasileiras na esfera pública. No caso do candomblé da Bahia, essa culturalização, como sublinhou Roger Sansi (2007), tem operado em conjunto com processos de reafricanização e dessincretização dos terreiros. Do sincretismo afro-católico passa-se àquilo que Sansi designou como o "sincretismo da cultura" (SANSI, 2007, p. 3).

Em São Luís, a inscrição do tambor de mina no espaço dos discursos e práticas sobre cultura não deixa de ter alguma relevância. Nos anos 1960, o governador estadual José Sarney não só mantinha uma relação pessoal forte com Pai Jorge Itaci (o então pai de santo da Casa de Iemanjá), como estendeu as suas políticas de reconhecimento e valorização da cultura popular do Maranhão ao tambor de mina. Foi então que se iniciou a participação de dançantes de tambor de mina em espetáculos públicos (que se mantém até hoje). Mais tarde, com a inauguração, em 1982, do Museu Domingos Vieira Filho, não foram só o bumba meu boi e as festas do Divino que entraram no espaço museológico, mas também o tambor de mina. E em 2002, o tombamento da Casa das Minas pelo IPHAN reforçou a inscrição do tambor de mina no regime patrimonial. Mas, comparativamente à Bahia, assim como por relação a outras expressões da cultura popular do Maranhão, o perfil patrimonial do tambor de mina é menos vincado. É nesse quadro que pode ser entendida a cooptação pelos terreiros dos discursos culturalistas sobre as festas do Divino: por seu intermédio, é a inscrição do tambor de mina no regime patrimonial que sai reforçada.

0 facto desse reforço do efeito patrimonial assentar sobre as festas e não - como na Bahia - sobre a reclamação da fidelidade à África, deve também ser sublinhado. 
De facto, em contraste com a Bahia, em São Luís é menor a importância dos processos de reafricanização dos terreiros. A maioria dos terreiros - mesmo aqueles, como a Casa das Minas e a Casa Fanti-Ashanti, em que o discurso africanista é mais enfático -, mantém também um vínculo importante com o catolicismo, expresso designadamente na continuada cooptação das festas do Divino. Faz portanto algum sentido que seja sobre as festas do Divino que recaia parte importante das expectativas de representação dos terreiros no regime patrimonial.

\section{Referências}

ALBERNAZ, L. S. F. 0 "urrou" do boi em Atenas: instituições, experiências culturais e identidade no Maranhão. 2004. 346 f. Tese (Doutorado em Ciências Sociais) - Instituto de Filosofia e Ciências Humanas, Universidade Estadual de Campinas/ Unicamp, Campinas, 2004.

BARBOSA, M. G. Umas mulheres que dão no couro: as caixeiras do Divino no Maranhão. São Paulo: Empório de Produções e Comunicações, 2006.

BARROS, A. E. A. 0 pantheon encantado: cultura e heranças étnicas na formação da identidade maranhense (1937-65). 2007. 317 f. Dissertação (Mestrado em Estudos Étnicos e Africanos) - Programa Multidisciplinar de Pós-Graduação em Estudos Étnicos e Africanos, Universidade Federal da Bahia/ UFBA, Salvador, 2007.

BRAGA, A. S. G.Folclore e política cultural: a trajetória de Domingos Vieira Filho e a institucionalização da cultura. 2000. 163 f. Dissertação (Mestrado em Políticas Públicas) - Programa de Ciências Sociais, Universidade Federal do Maranhão/UFMA, São Luís, 2000.

CARDOSO, L. C. M. 0 teatro do poder: cultura e política no Maranhão. 2008. 177 f. Dissertação (Mestrado em Ciências Sociais) - Programa de Pós-Graduação em Ciências Socias, Universidade Federal do Marnhão/UFMA, 2008.
CARVALHO, M. M. P. Matracas que desafiam o tempo: é o bumba meu boi do Maranhão. Um estudo de tradição/ modernidade na cultura popular. 1988. Dissertação (Mestrado) - Universidade Federal do Rio de Janeiro/UFRJ, Rio de Janeiro, 1988.

. O Divino maranhense no espaço sagrado das casas de culto afro I. Boletim da Comissão Maranhense de Folclore, n. 46, p. 9-12, 2010a.

O Divino maranhense no espaço sagrado das casas de culto afro II, Boletim da Comissão Maranhense de Folclore, n 47, p. 9-12, 2010 b.

COMPANHIA Barrica. Disponível em: <https://pt. wikipedia.org/wiki/Companhia_Barrica>. Acesso em: 7 jan. 2018

CUNHA, M. C. "Culture” and culture: Traditional knowledge and intellectual rights. Chicago: Prickly Paradygm Press, 2009.

EDUARD0, 0. C. The Negro in Northern Brazil: A study in acculturation. Seattle/London: University of Washington Press, 1948.

FERRETTI, S. F. Repensando o sincretismo: estudo sobre a Casa das Minas. São Paulo, São Luís: EDUSP/FAPEMA, 1995.

. La fête du Divin chez le tambour de mina. Comunicação apresentada à XXV CONFERÊNCIA DA SOCIÉTÉ INTERNATIONALE DE SOCIOLOGIE DES RELIGIONS. 1999. <htpp//www.ufma.br/canais/gpmina/textos/10.htm>. Acesso em: 7 set. 2007.

Tambor de crioula. Ritual e espectáculo. 3. ed. São Luís: Comissão Maranhense de Folclore, 2002 (1979).

. Perfil popular: Maria Michol Pinto de Carvalho. Boletim da Comissão Maranhense de Folclore, n. 53, p. 20, 2012.

. O longo declínio da Casa das Minas do Maranhão: um caso de suicídio cultural? Comunicação apresentada à 24. ${ }^{a}$ REUNIÃO BRASILEIRA DE ANTROPOLOGIA, Anais... São Paulo, PUC, 2012b. 
. A Dança de Lelê. São Luis: Fundação Cultural do Maranhão, 1977.

GONÇALVES, J. R. S.; LEAL, J. A. F. As festas do Divino Espírito Santo no Maranhão: uma aproximação de conjunto. Boletim da Comissão Maranhense de Folclore, n. 60, p. 10-17, 2016.

GOUVEIA, C. R. M. As esposas do Divino: poder e prestígio na festa do Divino Espírito Santo em terreiros de tambor de mina de São Luís do Maranhão. 2001. 156 f. Dissertação (Mestrado em Antropologia) - Universidade Federal de Pernambuco/UFPE, Recife, 2001.

GUSS, D. The festive state. Race, ethnicity and nationalism as cultural performance. Berkeley: University of California Press, 2000.

HAFSTEIN, V. Claiming culture: intangible heritage inc., folklore, traditional knowledge. In: HEMME, D.; TAUSCHEK M.; BENDIX. R. (Orgs.), Prädicat 'heritage'. Wertschöpfungen aus culturellen ressorcen, Munster, Lit Verlag, 2007, p. 75-100.

HANDLER, R. Nationalism and the Politics of Culture in Quebec. Madison: The Wisconsin University Press, 1988.

KIRSHENBLATT-GIMBLETT, B. Theorizing heritage. Ethnomusicology. v. 39, n. 3, p. 367-380, 1995.

Destination culture: Tourism, museums, and heritage. Berkeley: University of California Press, 1998.

LEAL, J. Festas do Divino em São Luís: um retrato de grupo. Boletim da Comissão Maranhense de Folclore, n. 53, p. 3-7, 2012.

- A festa maior dos terreiros: Divino e mina em São Luís (MA). Revista Pós Ciências Sociais, n. 21, p. 105-125, 2014.

. 0 Culto do Divino: migrações e transformações. Lisboa: Edições 70, 2017.

LIMA, L. C. Festa do Divino Espírito Santo em Alcântara (MA). Brasília: Ministério da Cultura/ Grupo de Trabalho de Alcântara, 1988 (1972).
0 Divino Espírito Santo (1. ${ }^{\text {a Parte). Bole- }}$ tim da Comissão Maranhense de Folclore, n. 22, p. 6-8, 2002a.

Reportagem-viagem ao Divino Espírito Santo dos Açores. Boletim da Comissão Maranhense de Folclore, n. 24, p. 14-16, $2002 b$.

- Memórias de Velhos: uma contribuição à memória oral da cultura popular maranhense. v. VI. São Luís: Secretaria do Estado da Cultura / Comissão Maranhense de Folclore, 2006.

MENDES, H. F. Do Espírito Santo à Trindade: um programa social de cristianismo inculturado. Porto: Universidade Católica Portuguesa, 2006.

NUNES, I. M. A. (Org.) Complexo cultural do bumba-meu-boi do Maranhão. Dossiê do registro. São Luís: IPHAN, 2011.

PACHECO, G.; GOUVEIA, C.; ABREU. M. C. Caixeiras do Divino Espírito Santo de São Luís do Maranhão. Rio de Janeiro. Associação Cultural Caburé, 2005.

PARODI, M. Il campo del folclore tra valorizzazione e integrazione culturale. Il caso di São Luís del Maranhão (Brasile). 2011. Tese. 397 f. (Doutorado em Antropologia da Contemporaneidade) Università degli Studi di Milano Bicocca, Milano-Italia, 2011.

RAPOSO, P. Virando o outro em Podence: máscaras da pós-ruralidade. Antropolítica, n. 30, p. 131-149, 2011.

ROCHA, M. F. S. A cada canto seu Esprito Santo. diversidade e unidade na terminologia da festa do Divino Espírito Santo. 2013. 425 f. Tese (Doutorado em Linguística) - Programa de Pós-Graduação em Linguística, Universidade Federal do Ceará/ UFC, Fortaleza, 2013.

SANSI, R. Fetishes and monuments. Afro-Brazilian art and culture in the 20th century. New York/ Oxford: Berghahn Books, 2007.

SANTOS, J. T. 0 poder da cultura e a cultura no poder. A disputa simbólica da herança cultural negra no Brasil. Salvador: EDUFBA, 2005. 
SANTOS, P. B. Alcântara: a sociologia da festa do Divino. São Luís: Fundação Instituto de Pesquisas Económicas e Sociais, 1980

VIEIRA FILHO, D. Folclore brasileiro: Maranhão, Rio de Janeiro: FUNARTE/Campanha de Defesa do Folclore Brasileiro, 1977.

Populário maranhense: bibliografia. São Luís: Secretaria da Cultura do Maranhão/Civilização Brasileira, 1982.

A festa do Divino Espírito Santo. Boletim da Comissão Maranhense de Folclore, n. 31, p. 12-14, 2005 (1954). 
RESUMO

Este artigo visa proceder ao exame das políticas e práticas de objetifıcação das festas do Divino de São Luís (Maranhão) e dos seus impactos nos terreiros de tambor de mina, onde se realiza a maioria das festas. Defende que um dos efeitos dessas políticas e práticas foi a culturalização das festas, isto é, a sua tematização em torno de ideias sobre cultura, raízes e tradição. Examina também os termos dessa culturalização. Esta deve ser vista não tanto como um processo de ressignificação radical das festas, mas como um processo de adição de um novo significado - cultural - aos significados - religiosos e sociais - que continuam a caracterizar as festas.

\section{PALAVRAS-CHAVE}

Religião; patrimônio, festa, tambor de mina, religiões afro-brasileiras.

\section{ABSTRACT}

This paper examines the politics and practices of cultural objectification related to Holy Ghost feasts in São Luís (Maranhão) and their impact in tambor de mina cult houses - where most feasts take place. It argues that one of the impacts of the objectification of the feasts has been their thematization around topics such as "culture", "roots" and "tradition". It also argues that the inclusion of the feasts in the "heritage regime" should not be seen - as in other cases - as a radical shift in their contents and meanings, but rather as a process of addition of a new "cultural" meaning to the religious and social meanings that continue to define the feasts.

\section{KEY WORDS}

Religion heritage, feast, tambor de mina, Afro-Brazilian religions. 